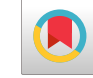

\title{
Nursing Students' Attitudes Toward and Satisfaction with Concept Map in Shahrekord University of Medical Sciences: A Mixed Method Study
}

\author{
Haydeh Heidari ${ }^{1}$ and Marjan Mardani-Hamooleh ${ }^{2, *}$ \\ ${ }^{1}$ Department of Pediatric Nursing, Modeling in Health Research Center, Faculty of Nursing and Midwifery, Shahrekord University of Medical Sciences, Shahrekord, Iran \\ ${ }^{2}$ Department of Psychiatric Nursing, Nursing Care Research Center, Faculty of Nursing and Midwifery, Iran University of Medical Sciences, Tehran, Iran \\ "Corresponding author: Department of Psychiatric Nursing, School of Nursing and Midwifery, Iran University of Medical Sciences, Tehran, Iran. Email: \\ mardanihamoole.m@iums.ac.ir
}

Received 2019 January 06; Revised 2019 December 14; Accepted 2019 December 16.

\begin{abstract}
Background: Clinical field is an important part of nursing education. Insufficiency in providing opportunities for learning practically not only gives rise to adverse consequences for students, but also affects educational programs and nursing profession.

Objectives: The aim of this study was to investigate nursing students' attitudes toward and satisfaction with concept map (CM). Methods: The present research is an embedded study. The qualitative stage included 18 nursing students of Shahrekord University of Medical Sciences in their 6th semester who were selected through purposive sampling. Content analysis was used for data analysis. Semi-structured individual interviews were conducted for data collection. The quantitative stage was implemented simultaneously with distribution of the researcher-made questionnaires among 48 students.

Results: Based on findings, four categories were obtained: competency of CM method, managing and organizing measures, promoting care services, and increasing critical thinking. In the quantitative stage, data were gathered by obtaining history from parents or children; $31.2 \%-68.8 \%$ agree with the quality of CM. Required information about disease was collected from parents and patient; $39.6 \%$ - 58.3\% agree and 2.1\% disagree. Different data from various sources (such as parents and children) were related; $43.7 \%$ $-54.2 \%$ agree and $2.1 \%$ disagree.

Conclusions: Considering that nursing process is now widely used in Iran at B.Sc. and M.Sc. levels, integrating CM to nursing process can be useful in nursing education.
\end{abstract}

Keywords: Concept Map, Teaching, Learning, Nursing Student

\section{Background}

The nursing process is a critical method for solving problems, removing needs and caring for patients. In fact, it is the systematic problem-solving point of view for offering care services and clinical decision-making (1). However, the results of a study revealed that nurses have a negative attitude toward care designs based on nursing process (2). Clinical field is an important part of nursing education. Insufficiency in providing the possibility for learning practically not only gives rise to adverse consequences for students, but also affects educational program and nursing profession (3).

Currently, nursing education should provide chances for students who can create helpful changes in the clinical environment (4). Therefore, the use of new teaching approaches such as concept map (CM) can be beneficial in nursing. CM is designed based on the inclusion of crosslinks; learning occurs by establishing relationships between new concepts and themes and those already stored in the learner's cognitive construction (5). Of course, the main disadvantages of CM are as follows: it needs some expertise to learn, it can be distinctive in conditions of design, and its complexity may not always assist memorability, and learners may feel devastated with designing CMs (6).

CM has been investigated in a variety of studies. Findings of an experimental study in the U.S. showed that nursing students in the CM group performed much better on the health education systems than students in the control group (7). A study in Brazil showed that CM is a valid strategy to assess the learning-teaching process and can be used for education, research and reflection in nursing (8). Findings of one study in France indicated that CM facilitated 
the development of metacognitive skills for nursing students (9). According to the results of a study in Taiwan, outcome-based CM could encourage students to take a biopsycho-social approach to medicine, which might finally result in better nursing care (10). In addition, based on the results of an Iranian study, using the CM would positively affect academic function of nursing students (11).

Taking into account the benefits already enumerated, the role of CM is important in nursing. However, the use of this technique is currently highly complex and multidimensional (12), for which the existing knowledge is not well explored in Iran. Although CM and its effects on education have been studied in some quantitative studies in Iran, no mixed- method studies have examined CM. The researcher's experiences in clinical teaching revealed that students are not satisfied with the nursing process. Of course mixed method approach can greatly increase our understanding of integrating CM with nursing process for nursing students. This method enhances comprehensiveness of overall findings. The researcher decided to do this approach with the aim of integrating $\mathrm{CM}$ with nursing process.

\section{Methods}

\subsection{Study Design}

The present research is an embedded study which was started simultaneously with gathering qualitative and quantitative data. Embedded research is mixed method research in which qualitative and quantitative stages are done simultaneously (13). Finally the results were merged.

\subsection{Embedded Method}

The present research is a mixed-method approach, where quantitative and qualitative stages were simultaneously collected using a convergent method. In a convergent method, the first set of information has a secondary and supportive role for the preliminary information; a method by a study design within another method. The researcher designs a large qualitative study within a smaller quantitative study in different stages at the same time. Also, pragmatism is research paradigm for mixed method study (13). At first, the researcher taught students how to use $\mathrm{CM}$, and asked them to take patient history from parents and list patient's problems, then draw up a conceptual map for each patient problem included objectives, planning, implementation and evaluation.

\subsubsection{Qualitative Stage}

In the qualitative stage, a descriptive qualitative study was conducted.

\subsubsection{Data Collection}

The present study was carried out in 2017 among nursing students who were completing their pediatrics course. Participants included 18 nursing students in their 6th semester, who were selected through purposive sampling. At first, nursing students were briefed on CM and asked to prepare a CM for every patient at each day of training. Finally, they were asked to explain their experiences about CM.

The interviews were conducted in the hospital and lasted 30 minutes. The interview started with the open question of "please talk about your experience of using CM in pediatrics course", and continued with probing questions. Sampling and data collection continued until data saturation occurred. Saturation happened with 18 interviews.

\subsubsection{Data Analysis}

Content analysis was used for data analysis. It is used for studies which are designed for describing a phenomenon. It is appropriate when theories or research articles are limited about a phenomenon. Content analysis has three distinct approaches: conventional, directed, or summative $(14,15)$. The conventional approach was used in this study.

The researcher listened to tapes several times and studied the data deeply to find a general point of view toward the interviews. All interviews were transcribed verbatim and key words were bolded to extract codes. After extracting concepts and codes from important sentences and paragraphs, they were classified according to their differences and similarities and finally, the subcategories were combined into main categories according to the relationship between them.

\subsubsection{Trustworthiness}

Rigor of the data was evaluated through credibility, dependability, confirmability and transferability (13). Ongoing scrutiny of the data and the subject was used to determine the credibility of the data. The research team's comments were used in relation to the interview process as well as the data analysis. The transcripts and the findings were returned to participants for comments and corrections. To determine the dependability of the data, the comments of an independent supervisor, who was familiar with nursing education and research methodology but was not part of the research team, were sought, and unanimous agreement was reached about the results. To determine confirmability of the data, all the activities were recorded, and a report was prepared on the research process. In order to determine the transferability, the results, 
shared with three nursing students who were not part of the research and had similar conditions, were confirmed.

\subsubsection{Ethical Considerations}

Participant's right to privacy and confidentiality was maintained according to the code of medical ethics. The objectives of the study and tape recording were explained to all participants. They were all assured of the privacy of their personal information and signed an informed consent form before participating in this study.

\subsubsection{Quantitative Stage}

The quantitative stage was done simultaneously with distribution of the questionnaire on the quality of CM.

\subsubsection{Data Collection}

Data were collected through a researcher-made questionnaire after obtaining written consent from 48 students who participated in this stage.

\subsubsection{Data Analysis}

The researcher-made questionnaires were gathered after students took patient history from parents or children. In the questionnaire: (1) gathered data was shown in CM, (2) patients' problems was listed based on CM, (3) shortterm goals were designed in CM for patient, and (4) the nursing measures, prioritized more clearly in CM than in nursing process, were studied. These domains were scored on Likert scale except for total score for quality of CM and satisfaction with CM. The last item was student satisfaction, which was scored from 0 to 100.

\subsubsection{Validity and Reliability}

The questionnaire was given 10 experts for calculating content validity ratio (CVR), which revealed all items were more than $76 \%$ in agreement. In this study, content validity index (CVI) was estimated as 0.81 . The content validity of the questionnaire was confirmed by asking expert opinion and its reliability was assessed through Cronbach's alpha of 9.

\section{Results}

\subsection{Qualitative Results}

The students' age ranged between 21 and 23 years old (12 female and 6 male). Based on data analysis, four categories emerged: competency of CM method, managing and organizing measures, promoting care services, and increasing critical thinking. Competency of CM method included three subcategories of being more practical, increased application, and self-confidence. The category of managing and organizing measures included three subcategories of expressing list of problems, expressing purposes and planning, performing and evaluating. The category of promoting care services included three subcategories of saving expenses, saving time, improving learning and increasing concentration and reasoning. The category of increasing critical thinking included subcategories of improving learning, increasing concentration and reasoning.

\subsubsection{Competency of CM Method}

This category had three subcategories of being more practical, increased application, and increasing selfconfidence.

Most students stated that CM is more practical and applicable. The students have more self-confidence by using this method. "CMwas a good experience because students can intervene more and can have a better relationship with clients. We gave the patient different training about problems which were useful for them and their accompanier. Students developed their information and had more self-confidence. The measures are more applicable" (Participant (P) 3 ).

"This method is more applicable and increased our performance. It is of course more interesting than nursing process and this will increase students' performance" (P5).

"CM is more applicable and appropriate than nursing process because nursing process only forces students to deliver their homework on paper, but CM requires better performance of students in ward" (P1).

\subsubsection{Managing and Organizing Measures}

The category of managing and organizing measures emerged from three subcategories: proposing list of problems, proposing purposes and planning, performing and evaluation.

Most students stated that patients' problems are listed one by one through CM, the purposes are planned and by taking action, measures are easily observable. "CM is a summary and the patient's problem can be listed easily and studied one by one... The problems are solved until the end of the shift and in this way they are not mixed... a problem can be solved well; the actions can be planned and taken" (P6).

Most students stated that through CM method, by organizing measures necessary training is given to families. "CM is good for organizing tasks. In a general view, we can realize what measures have been taken for the patient and their feedback. It saves time. Intervention prioritizations are easily seen and it is generally good for offering services" (P4).

"The important point is the training given to families and they benefit from this method" (P16).

"Nursing process is complex and cannot yield good results at the end of a shift because it has more of a diagnostic ap- 
proach. But in CM, patient's problems can be studied easily" (P8).

"In nursing process, we look more for details and diagnosis of diseases and less attention is paid to nursing measures. Students seek to find the reason of the disease and not to train the patient which is a major responsibility of nurses" (P17).

\subsubsection{Promoting Healthcare Services}

The major category of promoting healthcare services had three subcategories of saving expenses, saving time and improving learning and increasing concentration and reasoning.

Most students stated that most families occupy less hospital beds and thus reduce their expenses through CM and its effects.

"CM can decrease hospital congestion due to its applied effects on parents and family expenses, and optimize expenses" (P10).

"Training with this method will help families take care of their patient at home. It extends health stations and makes every house a health center. It also decreases expenses" (P15).

\subsubsection{Increasing Critical Thinking}

The major category of increasing critical thinking emerged from three subcategories of improving learning, concentration and reasoning.

Most students stated that CM improved their learning, concentration and reasoning. "CM has favorable effects on students' learning, effective learning and parents training, because it is complete and obvious in content" (P4).

In addition, the focus in CM is on training and nursing measures. Moreover, due to its attractiveness and newness of care, it has better and longer effect on learning. "We wrote nursing process for getting the mark, but CM is more committed to memory because it focuses on training measures" (P12).

"We could not train before; we just got information to write the process. But now we train the patient and I can remember all the care and training about different diseases. For example, during my training, a patient of mine had diarrhea, pneumonia, seizure and urinary tract infection. I remember all their care and training, but I don't remember what process I wrote for what disease in other wards" (P3).

"Through CM, we prioritized patient's problems by searching and gathering information. Then we planned appropriate measures by good reasoning and tried to get the favorable results until the end of the shift by evaluation. What is interesting is that if we did not get a result, we took other measures. For example, at the beginning of the shift, I gave 16 drops of acetaminophen to my patient who had fever, the fever reduced. I checked him four hours later, I knew that I could give him acetaminophen in case his fever had not reduced. But in another patient who had a seizure with $39^{\circ} \mathrm{C}$ fever, I gave a suppository. They both had fever but considering the information, I took different actions. The most important of all was sponge bath which none of the patients knew about" (P7).

"Considering previous training, nursing process looked like an assignment and had no role in our learning. It was just copying from a book and we did not train the patient. But learning process was more in CM. For example, we studied a lot about a special disease that a child suffered from, then we summarized the symptoms, purposes and care and drew it as CM. We trained the family and accompanier and it had an effective role in learning" (P6).

"This method was so useful in understanding and memorizing the disease. We understood the concept of nursing care, measures and purposes better" (P14).

\subsection{Quantitative Results}

In the quantitative stage, 48 students participated; 15 were male and 33 were female. The results of quantitative stage are shown (Table 1$)$.

\subsection{Mixed Method Results}

In our study, 4 major categories of competency of CM method, managing and organizing measures, promoting care services, and increase in critical thinking were obtained. Based on the results of the quantitative stage, data were gathered by obtaining history from parents or children; $68.8 \%$ totally agree, and $31.2 \%$ agree with the quality of CM. Required information about disease was collected from parents and patient; 58.3\% totally agree, 39.6\% agree and $2.1 \%$ disagree. Different data from various sources (such as parents and children) were related; $54.2 \%$ totally agree, $43.7 \%$ agree, and $2.1 \%$ disagree.

\section{Discussion}

The major category of competency of CM method emerged from three subcategories of being more practical, increased application, and self-confidence. The results of quantitative stage also confirmed these findings. Based on the results of quantitative stage, required information was gathered by obtaining history from parents or children, $68.8 \%$ totally agree, and $31.2 \%$ agree. Required information about disease was collected from parents and patients, 58.3\% totally agree, $39.6 \%$ agree and $2.1 \%$ disagree. Different data from various sources (such as parents and children) were related, $54.2 \%$ totally agree, $43.7 \%$ agree and 2.1\% disagree. Other studies also confirmed these findings. Based on the results of the research done in Iran, clinical application of CM led to promoted clinical skills of nursing students (16). The results of a study in the U.S. indicated that the use of CM provided nursing students with 


\begin{tabular}{|c|c|c|c|c|c|}
\hline & $\begin{array}{l}\text { Totally } \\
\text { Agree }\end{array}$ & Agree & No Idea & Disagree & $\begin{array}{c}\text { Totally } \\
\text { Disagree }\end{array}$ \\
\hline Required information was gathered from parents or children by obtaining history. & $33(68.8)$ & $15(31.2)$ & & & \\
\hline Required information was gathered about disease from parents and patient. & $28(58.3)$ & $19(39.6)$ & & $1(2.1)$ & \\
\hline Different data were collected from various sources (such as parents and children). & $26(54.2)$ & $21(43.7)$ & & $1(2.1)$ & \\
\hline Gathered data in CM were drawn up. & $34(70.8)$ & $14(29.2)$ & & & \\
\hline Patient's problem was listed based on CM. & $36(75.0)$ & $12(25.0)$ & & & \\
\hline Short-term goals were regulated in CM for patient. & $28(58.3)$ & $17(35.4)$ & $3(6.3)$ & & \\
\hline Nursing measures are prioritized more clearly in CM than in nursing process. & $34(70.8)$ & $14(29.2)$ & & & \\
\hline General score from quality of CM out of 100 & \multicolumn{5}{|c|}{94.12} \\
\hline Student satisfaction of CM out of 100 & \multicolumn{5}{|c|}{95.44} \\
\hline
\end{tabular}

Values are expressed as Frequency (\%).

a new insight at clinic and a better clinical judgment (17). Similarly, the findings of other studies showed that CM improves the skills of nursing students in practice $(3,18)$.

Based on results of the qualitative stage, the major category of managing and organizing measures emerged from three subcategories of expressing list of problems, expressing purposes and planning, performing and evaluating. The results of quantitative stage also confirmed these findings. The gathered data were displayed on $\mathrm{CM} ; 70.8 \%$ totally agree, and $29.2 \%$ disagree. Patient's problems were listed based on CM; $75 \%$ totally agree, and $25 \%$ agree. Shortterm goals were regulated in CM for patient; 58.3\% totally agree, $35.4 \%$ agree, and $6.3 \%$ no idea. Nursing measures are prioritized more clearly in CM than in nursing process; $70.8 \%$ totally agree and $29.2 \%$ agree. In this regard, the study of Lee et al. showed that using CM will result in learning and an increase in critical thinking (19).

Based on the results of the qualitative stage, the major category of promoting care services emerged from three subcategories of saving expenses, saving time, and decreasing hospital bed occupation. According to the results of the quantitative stage, it was confirmed that nursing measures are prioritized more clearly in CM than in nursing process. Based on the results of the qualitative stage, the major category of increasing critical thinking contained subcategories of improving learning, increasing concentration and reasoning. The results of the quantitative stage confirmed this finding. Based on the results of the quantitative stage, the quality of $\mathrm{CM}$ is $94.12 \%$ and the consent of CM is $95.44 \%$. The results of other studies also confirmed this finding. Acknowledging our research findings, results of a study suggested that CM assisted nursing students in dealing with clinical problems (20). Furthermore, one study indicated nursing students who applied
CM for their care projects enjoyed higher critical thinking skills (21). The results of a study also found that novice nurses could manage to promote their critical thinking by employing $\mathrm{CM}$ (22). The finding of a study showed that using CM increases students' critical thinking (23). In addition, Heidari and Mardani Hamooleh in Iran revealed that the skill of critical thinking is the basis for correct decisions which decreases expenses and increases quality of care (24). Therefore, the need for using critical thinking skills is stressed in the nursing profession in order to improve the quality of nursing care.

Our study provided a deep understanding into the perceptions of nursing students about the promotion of CM in education. Replacing nursing process with CM in nursing education is a new idea in Iran, and requires researchbased scientific foundations to develop. Our findings act as an applicable model for the promotion of clinical care in nursing education. Attending to the perceptions of nursing students about replacing nursing process with $\mathrm{CM}$ can help educational designers in developing more effective clinical courses.

The study also ran into some limitations such as not analyzing the perspective of other researchers involved in professional nursing education including the professors of this discipline. Therefore, it is recommended that on account of the important role these people play in the field of nursing education, similar qualitative studies be conducted. The small sample size and the qualitative nature of the study limit the generalizability of the results. However, as with all qualitative studies, the findings were not intended to be generalized. Nevertheless, the results of this study add to the body of knowledge in this area. 


\subsection{Conclusions}

Clinical experience is an important part of nursing training. The results of the present study revealed that using CM will deepen learning and increase critical thinking. In this method more attention is paid to patient and family training. Considering that nursing process is now widely used in Iran at bachelor's and master's levels, integrating CM to nursing process can be useful in nursing education. Of course, it needs similar studies in other nursing services.

\section{Acknowledgments}

The researchers are thankful to all of the participants.

\section{Footnotes}

Conflict of Interests: The authors declare that they have no competing interests.

Funding/Support: There was no funding/support for this study.

\section{References}

1. Taskin Yilmaz F, Sabanciogullari S, Aldemir K. The opinions of nursing students regarding the nursing process and their levels of proficiency in Turkey. J Caring Sci. 2015;4(4):265-75. doi: 10.15171/jcs.2015.027. [PubMed: 26744726]. [PubMed Central: PMC4699506].

2. Ramos LAR, de Carvalho EC, da Silva Canini SRM. [Opinion of nursing aids and nursing technicians about the nursing process]. Rev Eletron Enfermagem. 2009;11(1). Portuguese. doi:10.5216/ree.v11.46863.

3. Rahnama F, Mardani-Hamooleh M. Iranian nursing students' perceptions regarding use of concept mapping: A content analysis. Res Dev Med Educ. 2017;6(1):45-50. doi: 10.15171/rdme.2017.008.

4. Shellenbarger T, Robb M. Technology-based strategies for promoting clinical reasoning skills in nursing education. Nurse Educ. 2015;40(2):79-82. doi: 10.1097/NNE.0000000000000111. [PubMed: 25402714].

5. Moattari M, Soleimani S, Moghaddam NJ, Mehbodi F. Clinical concept mapping: Does it improve discipline-based critical thinking of nursing students? Iran J Nurs Midwifery Res. 2014;19(1):70-6. [PubMed: 24554963]. [PubMed Central: PMC3917188].

6. Davies M. Concept mapping, mind mapping and argument mapping: What are the differences and do they matter? Higher Education. 2011;62(3):279-301. doi:10.1007/s10734-010-9387-6.

7. Kaddoura M, Van-Dyke O, Yang Q. Impact of a concept map teaching approach on nursing students' critical thinking skills. Nurs Health Sci. 2016;18(3):350-4. doi: 10.1111/nhs.12277. [PubMed: 26891960].

8. Bittencourt GK, da Nobrega MM, Medeiros AC, Furtado LG. [Concept maps of the graduate programme in nursing: Experience report]. Rev Gaucha Enferm. 2013;34(2):172-6. Portuguese. doi: 10.1590/s198314472013000200022. [PubMed: 24015477].
9. Paucard-Dupont S, Marchand C. [Exploratory study of clinical reasoning in nursing students with concept mapping]. Rech Soins Infirm. 2014;(117):85-112. French. [PubMed: 25080627].

10. Hsu LL, Pan HC, Hsieh SI. Randomized comparison between objectivebased lectures and outcome-based concept mapping for teaching neurological care to nursing students. Nurse Educ Today. 2016;37:8390. doi: 10.1016/j.nedt.2015.11.032. [PubMed: 26725013].

11. Jaafarpour M, Aazami S, Mozafari M. Does concept mapping enhance learning outcome of nursing students? Nurse Educ Today. 2016;36:12932. doi: 10.1016/j.nedt.2015.08.029. [PubMed: 26383908].

12. Jamison T, Lis GA. Engaging the learner by bridging the gap between theory and clinical competence: The impact of concept mapping and simulation as innovative strategies for nursesensitive outcome indicators. Nurs Clin North Am. 2014;49(1):69-80. doi: 10.1016/j.cnur.2013.11.004. [PubMed: 24485188].

13. Creswell J, Plano Clark V. Designing and conducting mixed methods research. 3nd ed. Thousand Oaks, CA: Sage Publications; 2018.

14. Graneheim UH, Lundman B. Qualitative content analysis in nursing research: Concepts, procedures and measures to achieve trustworthiness. Nurse Educ Today. 2004;24(2):105-12. doi: 10.1016/j.nedt.2003.10.001. [PubMed:14769454].

15. Elo S, Kyngas $H$. The qualitative content analysis process. J Adv Nurs. 2008;62(1):107-15. doi: 10.1111/j.1365-2648.2007.04569.x. [PubMed: 18352969].

16. Rasoul Zadeh N, Sadeghi Gandomani H, Delaram M, Parsa Yekta Z. Comparing the effect of concept mapping and conventional methods on nursing students' practical skill score. Nurs Midwifery Stud. 2015;4(3). e27471. doi: 10.17795/nmsjournal27471. [PubMed: 26576441] [PubMed Central: PMC4644603].

17. Gerdeman JL, Lux K, Jacko J. Using concept mapping to build clinical judgment skills. Nurse Educ Pract. 2013;13(1):11-7. doi: 10.1016/j.nepr.2012.05.009. [PubMed: 22698820].

18. Ferreira PB, Cohrs CR, De Domenico EB. [Software CMAP TOOLS to build concept maps: An evaluation by nursing students]. Rev Esc Enferm USP. 2012;46(4):967-72. Portuguese. doi: 10.1590/s008062342012000400026. [PubMed: 23018409].

19. Lee W, Chiang CH, Liao IC, Lee ML, Chen SL, Liang T. The longitudinal ef fect of concept map teaching on critical thinking of nursing students. Nurse Educ Today. 2013;33(10):1219-23. doi: 10.1016/j.nedt.2012.06.010. [PubMed: 22795871].

20. Atay S, Karabacak U. Care plans using concept maps and their effects on the critical thinking dispositions of nursing students. Int J Nurs Pract. 2012;18(3):233-9. doi: 10.1111/j.1440-172X.2012.02034.x. [PubMed: 22621292].

21. George A, Geethakrishnan R, D'Souza P. Concept mapping: A child health nursing practical exercise. Holist Nurs Pract. 2014;28(1):43-7. doi: 10.1097/HNP.0000000000000001. [PubMed: 24304630].

22. Wahl SE, Thompson AM. Concept mapping in a critical care orientation program: A pilot study to develop critical thinking and decisionmaking skills in novice nurses. J Contin Educ Nurs. 2013;44(10):455-60. doi: 10.3928/00220124-20130916-79. [PubMed: 24053130].

23. Chen SL, Liang T, Lee ML, Liao IC. Effects of concept map teaching on students' critical thinking and approach to learning and studying. J Nurs Educ. 2011;50(8):466-9. doi: 10.3928/01484834-20110415-06. [PubMed: 21524017].

24. Heidari H, Mardani Hamooleh M. Nursing students' experiences regarding nursing process: A qualitative study. Res Dev Med Educ 2016;5(2):101-4. doi:10.15171/rdme.2016.021. 